\title{
Pertambahan Biomassa dan Produksi Minyak Atsiri Tanaman Selasih (Ocimum basilicum L.) pada Usia Panen yang Berbeda
}

\section{Increase in Biomass and Essential Oil Production of Basil Plants (Ocimum basilicum L.) at Different Harvest Ages}

\author{
Rasyid Abdul Aziz*, Sri Widodo Agung Suedy, Munifatul Izzati \\ Program Studi Biologi, Fakultas Sains dan Matematika, Universitas Diponegoro \\ Jl. Prof. Soedarto, SH, Tembalang, Semarang 50275, Indonesia \\ *Email : rasyidabdulaziz94@gmail.com
}

Diterima 15 Juli 2021 / Disetujui 14 Agustus 2021

\begin{abstract}
ABSTRAK
Selasih (Ocimum basilicum L.) memiliki kandungan minyak atsiri yang dapat digunakan dalam industri kosmetik, parfum, dan medis. Penelitian ini bertujuan mengetahui hubungan usia panen dengan biomassa dan produksi minyak atsiri pada organ daun serta batang selasih. Penelitian menggunakan Rancangan Acak Lengkap (RAL) pola faktorial, dengan faktor pertama usia panen $(1 ; 1,5$; dan 2 bulan), dan faktor kedua organ tanaman (daun dan batang). Media tanam menggunakan tanah dan kompos (1:1) yang dimasukkan dalam polibag ukuran $30 \mathrm{~cm} \times 30 \mathrm{~cm}$, dan diberi naungan paranet $25 \%$. Parameter yang diamati: data pertumbuhan (tinggi tanaman, jumlah daun dan cabang primer), biomassa, dan produksi minyak atsiri. Analisis data menggunakan Anaylysis of Variance (ANOVA) dan Duncan's Multiple Range Test (DMRT) pada taraf kepercayaan $95 \%$. Penelitian menunjukkan hasil bahwa tanaman yang dipanen pada umur lebih tua menunjukkan pertumbuhan, biomassa dan produksi minyak atsiri yang lebih tinggi. Pada usia 1,5 bulan, biomassa meningkat $114,485 \%$ dibanding usia 1 bulan, sedangkan pada usia 2 bulan, peningkatan biomasa 91,410\% dibanding usia1,5 bulan. Produksi minyak atsiri tertinggi dihasilkan oleh organ daun pada usia panen 2 bulan sebesar $0,273 \mathrm{~g}$, dan $0,023 \mathrm{~g}$ pada organ batang. Kesimpulan penelitian ini menunjukkan bahwa usia panen berbeda berpengaruh nyata terhadap biomassa dan produksi minyak atsiri tanaman selasih.
\end{abstract}

Kata kunci : biomasa, konsentrasi, produksi, minyak atsiri, selasih, usia panen

\begin{abstract}
Basil (Ocimum basilicum L.) contains essential oils that can be used in the cosmetic, perfume, medical industries. This study aims to determine the relationship between harvest age and biomass and essential oil production in basil leaves and stems. The study used a completely randomized design (CRD) with a factorial pattern, with the first factor being harvest age $(1 ; 1.5$; and 2 months), and the second factor being plant organs (leaves and stems). The planting medium used soil and compost $(1: 1)$ which was put in $30 \mathrm{~cm} \times 30 \mathrm{~cm}$ polybags and was given a 25\% para net shade. Parameters observed: growth data (plant height, number of leaves, and primary branches), biomass, and essential oil production. Data analysis used Analysis of Variance (ANOVA) and Duncan's Multiple Range Test (DMRT) at a 95\% confidence level. Research shows that plants harvested at an older age show higher growth, biomass, and essential oil production. At the age of 1.5 months, biomass increased by $114.485 \%$ compared to the age of 1 month, while at the age of 2 months, the increase in biomass was $91.410 \%$ compared to the age of 1.5 months. The highest essential oil production was produced by leaf organs at 2 months of harvesting at $0.273 \mathrm{~g}$, and $0.023 \mathrm{~g}$ in stem organs. The conclusion of this study showed that different harvest ages had a significant effect on the biomass and essential oil production of basil plants.
\end{abstract}

Keywords: biomass, concentration, production, essential oil, basil, harvest age 


\section{PENDAHULUAN}

Selasih (Ocimum basilicum L.) adalah salah satu tanaman golongan terna, yang mudah dijumpai di Indonesia dan negara tropis lainnya. Seluruh bagian tanaman ini bisa dimanfaatkan sehingga menjadikannya sebagai salah satu tanaman potensial untuk dikembangkan (Rahimah dkk, 2015). Selain bijinya, potensi lain dari selasih adalah kandungan minyak atsirinya yang merupakan salah satu komponen bernilai komersial tinggi. Kardinan (2009) dan Khair-ulBariyah (2012) menyatakan bahwa kandungan minyak atsiri tanaman selasih terbukti dapat digunakan sebagai obat antiradang, antimikroba, antivirus, hipolipidemia, antioksidan dan dapat meningkatkan sistem imun tubuh.

Minyak atsiri adalah salah satu minyak nabati tersusun dari senyawa kompleks. Minyak atsiri terdiri dari berbagai senyawa hasil metabolit sekunder yang memainkan peran tertentu (Julianto, 2016). Minyak atsiri dapat ditemukan diberbagai organ tanaman, baik akar, batang, daun, bunga hingga biji (Rusli, 2010; Naeem et. al., 2018 ). Kardinan (2003), menyatakan bahwa konsentrasi minyak atsiri pada selasih sangat bervasiasi antar organ, dengan presentase berkisar $0,18 \%$ pada daun, $0,7 \%$ pada bunga dan $0,01 \%$ pada rantingnya. Feijo et al. (2014), menambahkan bahwa beberapa faktor lingkungan akan mempengaruhi kandungan, hasil dan konstituen dari minyak atsiri. Penelitian Sholeha dkk (2018), menunjukkan bahwa pemberian pupuk fosfat SP36 sebanyak 3.0g serta naungan $25 \%$ dapat meningkatkan biomassa tajuk dan produksi minyak atsiri pada tanaman selasih.

Sumarni (2008), menyatakan bahwa kualitas minyak atsiri dipengaruhi oleh berbagai faktor, termasuk umur tanaman. Hasil penelitian Rowshan dkk (2012) tentang minyak atsiri yang diperoleh dari daun Myrtus communis (murad, sejenis tanaman hias), menunjukkan bahwa pada tanaman yang berusia lebih muda menghasilkan minyak atsiri lebih banyak. Sebaliknya, penelitian Geng et. al (2011) tentang minyak atsiri pada kulit batang Cassia cinnamomum (kayu manis Tiongkok) menunjukkan bahwa tanaman berusia lebih tua menghasilkan minyak atsiri lebih banyak. Secara tidak langsung usia panen dapat meningkatkan produksi minyak atsiri, karena dapat meningkatkan biomassa tanaman..

Penelitian ini dilakukan dengan tujuan untuk mengetahui peningkatan produksi biomassa dan minyak atsiri pada batang dan daun selasih (Ocimum basillicum L.) ketika dipanen pada umur yang berbeda, sehingga diperoleh informasi waktu panen serta organ tanaman yang tepat pada budidaya selasih.

\section{METODE PENELITIAN}

\section{Waktu dan Tempat}

Penelitian menggunakan 2 tahap, yaitu tahap budidaya dan destilasi. Tahap budidaya dilakukan pada bulan Oktober 2020 hingga Desember 2020 di kebun yang berlokasi di Kabupaten Sukoharjo, Jawa Tengah. Tahap destilasi dimulai dari bulan Januari 2021 hingga Februari 2021, di Laboratorium Biologi Struktur dan Fungsi Tumbuhan, Departemen Biologi, FSM, Universitas Diponegoro, Semarang.

\section{Cara Kerja}

Biji selasih ditumbuhkan pada tray semai yang telah diberi media persemaian dan dipelihara sampai biji berkecambah dan mulai tumbuh batang dan memiliki 6 helai daun. Media tanam yang terdiri campuran tanah dan kompos (1:1) dimasukkan kedalam polybag ukuran $30 \mathrm{~cm} \mathrm{x}$ $30 \mathrm{~cm}$. Naungan dibuat menggunakan paranet $25 \%$, dengan tinggi $1 \mathrm{~m}$. Setelah berusia 3 minggu, bibit yang mempunyai daun sebanyak 6 helai dipindahkan ke dalam polybag yang telah diisi media tanam. Masing-masing polybag diisi 1 bibit, diberi 3g pupuk fosfat (Sholehab dkk, 2018). Tanaman dipelihara dengan melakukan penyiraman, penyiangan, dan pengendalian hama. Pengamatan pertumbuhan tanaman dilakukan ketika tanaman telah memasuki usia panen. Variabel pengamatan meliputi tinggi, jumlah daun dan jumlah cabang primer. Pemanenan dilakukan setelah tanaman mencapai usia yang dibutuhkan (1, 1,5 dan 2 bulan). Hasil panen yang didapat 
dipisahkan antara batang, daun dan akarnya, dikering anginkan, ditimbang berat kering (biomassanya), lalu dibawa ke Laboratorium untuk isolasi minyak atsiri. Isolasi minyak atsiri menggunakan metode destilasi uap air (Suardhika, 2018). Masing-masing sampel (daun dan batang) yang telah kering diambil sebanyak 100 gr dan didestilasi menggunakan air $500 \mathrm{ml}$ selama 1,5 jam. Hasil destilasi ditimbang, lalu dihitung konsentrasi dan produksinya. Setiap sampel diukur dan diulang sebanyak 3 kali. Konsentrasi minyak atsiri yang dihasilkan dari detilasi daun dan batang dihitung dengan rumus :

$$
\frac{\text { Berat SampelMinyak }(g)}{\text { Berat Sampel }(g)} \times 100 \% \text {. }
$$

Produksi minyak atsiri dihitung menggunakan rumus : Biomassa Tanaman $\times$ Konsentrasi Minyak Atsiri.

Penelitian menggunakan Rancangan Acak Lengkap (RAL) pola faktorial, yaitu faktor pertama usia panen (1, 1,5 dan 2 bulan) dan faktor kedua organ tanaman (daun dan batang). Data dianalisis dengan ANOVA dan uji DMRT (Duncan's Multiple Range Test) taraf signifikansi $5 \%$ menggunakan software SPSS.

\section{HASIL DAN PEMBAHASAN}

\section{Pertumbuhan dan biomassa}

Hasil penelitian dan analisis statistik menunjukkan pengaruh perbedaan usia panen terhadap pertumbuhan dan biomassa tanaman ditunjukkan oleh Tabel 1. Berdasarkan data tersebut menunjukkan masing-masing variabel pertumbuhan dan biomassa terdapat perbedaan yang signifikan. Data menunjukkan perbedaan usia panen menyebabkan tanaman yang berusia lebih tua memiliki tinggi, daun dan cabang primer serta biomassa meningkat. Pada tinggi tanaman, terdapat perbedaan nyata ketika antara tanaman usia 1 bulan dengan 1,5 bulan, namun antara usia 1,5 bulan dengan 2 bulan tidak terdapat perbedaan signifikan. Hal ini dikarenakan pada usia 1 hingga 1,5 bulan pertumbuhan tanaman didominasi oleh pertumbuhan vegetatif. Solikin (2012) menyatakan bahwa pertumbuhan vegetatif menyebabkan organ-organ vegetatif (daun, batang dan akar) mengalami pertambahan ukuran, volume, jumlah dan bentuk. Proses tersebut berawal dari terbentuknya daun saat perkecambahan hingga munculnya organ generatif. Memasuki usia 1,5 bulan hingga 2 bulan, dominasi pertumbuhan vegetatif mulai berkurang, dan digantikan dengan fase pertumbuhan generatif. Hal tersebut dibuktikan dengan munculnya primordia bunga saat usia 1,5 bulan, hingga terbentuk bunga sempurna pada tanaman usia 2 bulan.

Data pada jumlah daun menujukkan adanya perbedaan yang nyata di antara usia panen tanaman yang berbeda. Seiring bertambahnya usia, daun pada tanaman meningkat. Hal ini dikarenakan tanaman yang lebih tua memiliki waktu yang lebih banyak untuk menumbuhkan daun. Pertumbuhan daun diawali dengan terbentuknya primordial daun pada meristem apeks. Saat daun primordial baru terbentuk, daun primordial yang lebih tua secara bertahap berkembang karena aktivitas meristem di dalam daun. Primordial daun terus tumbuh hingga mencapai ukuran dan bentuk tertentu. Mulyani (2020) menyatakan bahwa peningkatan ukuran daun disebabkan oleh jumlah dan ukuran sel yang meningkat seiring bertambahnya usia. Pertumbuhan daun dikendalikan oleh faktor genetik dan juga faktor lingkungan yang ada, seperti intensitas cahaya, fotoperiode, air dan nutrisi yang tersedia.

Data pertumbuhan juga menunjukkan adanya perbedaan signifikan pada jumlah cabang primer tanaman. Perbedaan nyata terdapat pada tanaman usia 2 bulan, dengan jumlah cabang primer terbanyak, sedangkan antara tanaman usia 1 bulan dengan 1,5 bulan tidak terdapat perbedaan yang nyata. Hal tersebut disebabkan waktu pertumbuhan yang lebih lama sehingga tanaman memiliki batang pokok yang lebih panjang. Batang pokok yang lebih panjang akan meningkatkan jumlah cabang primer yang dihasilkan.

Biomassa merupakan berat total suatu organisme dalam area atau skala tertentu (Sahala dkk, 2013). Biomassa diartikan juga sebagai berat kering total suatu organisme (Sutaryo, 2009). Data pada variabel biomassa (berat kering) menunjukkan perbedaan signifikan dimiliki oleh 
tanaman usia 2 bulan, sedangkan yang dipanen pada usia 1 dan 1,5 bulan tidak menunjukkan perbedaan yang nyata. Tanaman usia 2 bulan juga memiliki biomassa paling tinggi. Antara tanaman usia panen 1 bulan dengan 1,5 bulan menunjukkan peningkatan biomassa sebesar 11,050g $(114,485 \%)$, sementara pada tanaman usia panen 2 bulan menunjukkan peningkatan biomassa sebesar 17,140g $(91,410 \%)$ dibandingkan usia panen 1,5 bulan. Peningkatan biomassa sangat berkaitan erat dengan pertumbuhan. Usia yang lebih tua menyebabkan tanaman memiliki pertumbuhan yang lebih tinggi. Peningkatan pertumbuhan juga akan menyebabkan biomassa pada tanaman ikut meningkat. Pada akhirnya metabolit yang disimpan oleh tanaman juga ikut meningkat. Menurut Hariyani (2015) biomassa tanaman adalah indikasi besarnya fotosintat yang dihasilkan selama pertumbuhan, dan besarnya fotosintat yang dihasilkan dipengaruhi oleh jumlah daun. Tuah, dkk (2017) menambahkan fotosintat disimpan sebagai materi organik dalam bentuk biomassa tanaman.

Tabel 1. Rerata Pertumbuhan dan Biomassa Tanaman Selasih (Ocimum basilicum L) pada Usia Panen Berbeda

\begin{tabular}{lcccc}
\hline $\begin{array}{c}\text { Usia Panen } \\
\text { (bulan) }\end{array}$ & $\begin{array}{c}\text { Tinggi Tanaman } \\
(\mathrm{cm})\end{array}$ & $\begin{array}{c}\text { Jumlah Daun } \\
(\text { helai) }\end{array}$ & $\begin{array}{c}\text { Jumlah Cabang Primer } \\
(\text { batang })\end{array}$ & $\begin{array}{c}\text { Biomassa } \\
(\mathrm{g})\end{array}$ \\
\hline 1 Bulan & $44,17^{\mathrm{a}}$ & $442^{\mathrm{a}}$ & $16^{\mathrm{a}}$ & $7,81^{\mathrm{a}}$ \\
1,5 Bulan & $63,38^{\mathrm{b}}$ & $780^{\mathrm{b}}$ & $16^{\mathrm{a}}$ & $18,86^{\mathrm{a}}$ \\
2 Bulan & $68,12^{\mathrm{b}}$ & $1303^{\mathrm{c}}$ & $20^{\mathrm{b}}$ & $36,10^{\mathrm{b}}$ \\
\hline
\end{tabular}

Keterangan : angka diikuti huruf sama dalam kolom yang sama menunjukkan tidak berbeda nyata menurut hasil uji DMRT taraf signifikansi $5 \%$

\section{Konsentrasi dan Produksi Minyak Atsiri}

Konsentrasi merupakan hasil dari perhitungan minyak atsiri yang didapat dalam setiap $100 \mathrm{~g}$ masing-masing sampel, sedangkan produksi merupakan hasil perkalian dari konsentrasi minyak atsiri yang didapat dengan keseluruhan biomassa setiap tanaman. Hasil analisis pengaruh usia panen yang berbeda terhadap konsentrasi minyak atsiri pada organ daun dan batang tanaman selasih tersaji dalam Gambar $1 \mathrm{a}$ dan $1 \mathrm{~b}$.

Berdasarkan hasil uji analisis ANOVA menunjukkan adanya interaksi antara faktor usia panen dengan faktor organ tanaman terhadap produksi konsentrasi minyak atsiri selasih. Pada tanaman usia 1 bulan terlihat tidak adanya perbedaan signifikan antara konsentrasi minyak atsiri pada daun maupun batang. Hal ini diduga disebabkan pertumbuhan tanaman masih berada pada tahap fase vegetatif. Karbohidrat yang merupakan substrat pembentukkan minyak atsiri, pada fase ini digunakan untuk pembelahan, pemanjangan, dan awal diferensiasi sel. Semua proses tersebut menyebabkan pertumbuhan batang, daun dan sistem perakaran berlangsung, sehingga menyebabkan konsentrasi pada kedua organ tersebut (batang dan daun) tidak berbeda signifikan secara statistik. Hal berbeda ditunjukkan oleh tanaman usia 1,5 bulan dan 2 bulan, yang menunjukkan adanya perbedaan yang nyata antara konsentrasi minyak atsiri di batang dan di daun. Hal tersebut dikarenakan oleh faktor usia panen yang semakin tua menyebabkan konsentrasi minyak atsiri pada daun meningkat, namun minyak pada batang semakin menurun.

Konsentrasi minyak atsiri pada daun yang meningkat dikarenakan daun merupakan tempat utama proses metabolisme (fotosintesis dan respirasi) berlangsung bagi tanaman. Peningkatan konsentrasi pada daun diduga disebabkan juga karena tanaman yang lebih tua memiliki organ daun yang lebih banyak. Hal tersebut berdampak pada peningkatan kapasitas fotosintesis tanaman, sehingga menghasilkan fotosintat yang lebih banyak. Fotosintat tersebut kemudian digunakan sebagai substrat dalam pembentukan minyak atsiri. Kridarti dkk (2012) menyatakan fotosintesis menghasilkan fotosintat berupa karbohidrat yang akan berperan sebagai substrat biosintesis minyak 
atsiri. Melalui proses glikolisis, karbohidrat akan diubah menjadi piruvat yang selanjutnya akan digunkan dalam pembentukan metabolit sekunder melalui jalur asam mevalonat (MVA) dan jalur metileritritol fosfat (MEP). Dari kedua jalur tersebut menghasilkan kerangka dasar isopren pada isopentenil difosfat (IPP). Bersama dengan bentuk diisomerasi (difosfat dimethylallyl DMAPP) membentuk unit biologis isopren. Isopren merupakan kerangka dasar dalam pembentukkan senyawa terpenoid (Nugroho, 2018). Warsito (2018) meyatakan bahwa minyak atsiri termasuk dalam golongan senyawa terpenoid.
Penurunan konsentrasi minyak atsiri pada batang diduga dikarenakan oleh munculnya organ generatif (bunga) pada tanaman yang lebih tua. Hal tersebut dibuktikan dengan munculnya organ bunga, yang dimulai dari munculnya primordia bunga pada tanaman usia 1,5 bulan, lalu menghasilkan bunga dewasa yang ada pada tanaman usia 2 bulan. Munculnya organ bunga tersebut menyebabkan berbagai hasil metabolit yang awalnya digunakan untuk pertumbuhan batang didistribusikan menuju organ bunga, termasuk minyak atsiri.

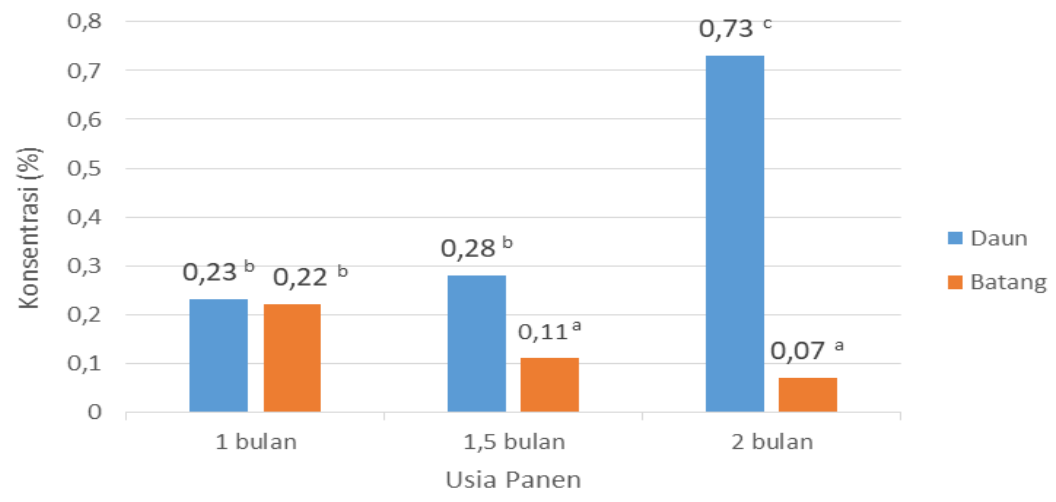

Gambar 1a. Diagram pengaruh usia panen terhadap konsentrasi minyak atsiri pada daun dan batang selasih (Ocimum basillicum L.). Angka diikuti huruf sama menunjukkan tidak berbeda nyata menurut hasil uji DMRT taraf signifikansi $5 \%$

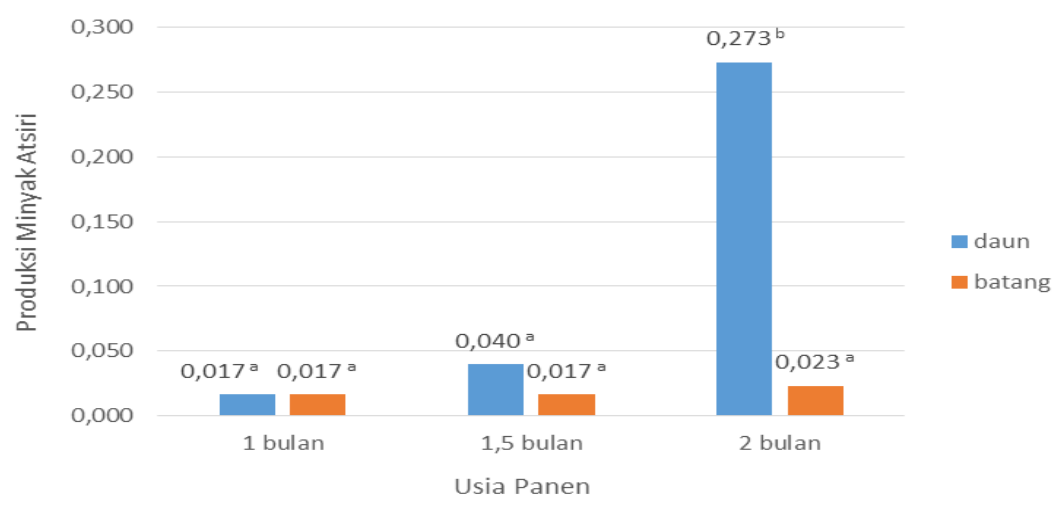

Gambar 1b. Diagram pengaruh usia panen terhadap produksi minyak atsiri pada daun dan batang selasih (Ocimum basillicum L.). Angka diikuti huruf sama menunjukkan tidak berbeda nyata menurut hasil uji DMRT taraf signifikansi $5 \%$

Berdasarkan data konsentrasi tersebut juga menunjukkan secara keseluruhan minyak atsiri yang dihasilkan oleh daun lebih banyak dibandingkan dengan batang. Hal ini dikarenakan daun merupakan organ tempat proses metabolisme berlangsung, khususnya fotosintesis. Sedangkan batang merupakan organ distributor hasil metabolit ke seluruh tubuh tanaman. Hasil tersebut juga diperkuat dengan hasil penelitian Feriyanto dkk (2013) yang memperlihatkan bahwa organ daun 
pada serai wangi (Cymbopogon winterianus) menghasilkan konsentrasi minyak atsiri lebih banyak $(1,52 \%)$ daripada organ batang $(1,03 \%)$.

Data hasil penghitungan konsentrasi minyak atsiri tersebut selanjutnya dikalikan dengan biomassa untuk mendapatkan data jumlah produksi minyak atsiri. Data tersebut disajikan pada Gambar 1b, yang menunjukkan bahwa secara statistik perbedaan yang nyata hanya terdapat pada produksi minyak atsiri daun tanaman selasih usia panen 2 bulan, sedangkan pada usia panen 1 dan 1,5 bulan tidak menunjukkan perbedaan yang nyata antara organ batang dan daun. Hasil tersebut juga menunjukkan bahwa daun yang dipanen pada usia 2 bulan menghasilkan minyak atsiri paling tinggi dibandingkan usia panen lainnya. Kondisi ini dapat terjadi dikarenakan ketika tanaman dipanen usia 2 bulan memiliki biomassa yang paling tinggi, selain itu diperkuat lagi dengan adanya peningkatan konsentrasi minyak atsiri pada daun yang berusia lebih tua. Hasil tersebut juga memperkuat pendapat Kardinan (2003), yang menyatakan bahwa konsentrasi minyak atsiri pada tanaman selasih bervariasi dengan persentase terbesar terdapat pada daun (berkisar 0,18\%), sedangkan persentase paling sedikit terdapat pada batang (berkisar 0,01\%). Berdasarkan penelitian ini dapat diketahui bahwa untuk menghasilkan produksi minyak atsiri dari tanaman selasih yang optimal dan efisien adalah dengan mendestilasi daun yang berasal dari tanaman usia panen 2 bulan.

\section{KESIMPULAN}

Usia panen yang berbeda terbukti dapat meningkatkan produksi minyak atsiri, sehingga dapat digunkan sebagai alternatif dalam perkembagan industri minyak atsiri. Penelitian juga menunjukkan bahwa usia panen memberi pengaruh yang berbeda pada konsentrasi minyak atsiri tanaman selasih, tergantung organ apa yang diambil. Minyak atsiri dari daun selasih lebih baik diambil ketika tanaman berusia lebih tua karena memiliki konsentrasi yang lebih tinggi, sedangkan minyak atsiri pada batang sebaliknya.

\section{DAFTAR PUSTAKA}

Feijo, E.V.R.S., Oliveira, R.A., dan Costa, L.C.B. (2014). Light affects Varronia curassavica essential oil yield by increasing trichomes frequency. Rev. Bras. Farmacogn, 24:516523.

https://doi.org/10.1016/j.bjp.2014.10.005

Feriyanto, YE. (2013). Pengambilan minyak atsiri dari daun dan batang serai wangi (Cymbopogon winterianus) menggunakan metode destilasi uap dan air dengan pemanasan microwave. Jurnal Teknik Pomits, 2 (01).

Geng, S., Cui, Z., Huang, X., Chen, Y., Xu, D., dan Xiong, P. (2011). Variations in essential oil yield and composition during Cinnamomum cassia bark growth. Industrial Crops and Products, $\quad 33: \quad 248-252$. https://doi.org/10.1016/j.indcrop.2010.10.01 8

Hariyani, Widaryanto, E., dan Herlina, N. 2015. Pengaruh umur panen terhadap rendemen dan kualitas minyak atsiri tanaman nilam (Pogostemon cablin Benth.). Jurnal Produksi Tanaman, 3 (3) : $206-211$

Julianto, T S. (2016). Minyak atsiri bunga Indonesia. Yogyakarta : Deepublish.

Kardinan, A. (2003). Selasih : Tanaman keramat multi manfaat. Jakarta : Agromedia

Kardinan, A. (2009). Penggunaan selasih dalam pengendalian hama lalat buah pada mangga. J. Littri, 15:101-109. https://doi.org/10.21082/jlittri.v15n3.2009.101109

Khair-ul-Bariyah, S., D. Ahmed, M. Ikram. (2012). Ocimum bacilicum: A review on phytochemical and pharmacological studies. $\begin{array}{llll}\text { Pak. J. } & \text { Che, . 2:78-85. }\end{array}$ https://doi.org/10.15228/2012.v02.i02.p05

Kridarti, E.M., Prihastanti, E., dan Haryanti, S. (2012). Rendemen minyak atsiri dan diameter organ serta ukuran sel minyak atsiri tanaman adas (Foeniculum vulgare Mill.) yang dibudidayakan di Kabupaten Semarang dan Kota Salatiga. Buletin Anatomi dan Fisiologi, 20 (1)

Mulyani, S. (2020). Anatomi tumbuhan. Yogyakarta: Kanisius.

Nasib, T., Sulaeman, R. dan Yoza, D. (2017). Penghitungan biomassa dan karbon di atas permukaan tanah di hutan larangan adat rumbio Kab. Kampar. JOM Faperta UR, 4 (1): $1-10$. 
Naeem, A., Abbas1, T., Ali, T.M., and Hasnain, A. (2018). Essential oils: Brief background and uses. Remedy Publications LLC, 1.

Nugroho, L.H. 2018. Jaringan sektretori tumbuhan. Yogyakarta: Gadjah Mada Universiy Press

Rahimah, S., Hendrarti, W. dan Ramlah, S. (2015). Uji aktifitas ekstrak biji selasih (Ocimum basilicum L.) dengan beberapa pelarut sebagai antipiretik pada mencit (Mus muculus). As-Syifaa, 07(02) : 158-163 https://doi.org/10.33096/jifa.v7i2.7

Rowshan, V., Najafian, S., dan Tarakemeh, A. (2012). Essential oil chemical composition changes affected by leaf ontogeny stages of myrtle (Myrtus communis L.). International Journal of Medicinal and Aromatic Plants, 2: 114-117.

Rusli, M.S. (2010). Sukses Memproduksi Minyak Atsiri. Jakarta : PT Agromedia Pustaka

Sahala, M.M., Rauf, A. dan Razali. (2013). Kajian Biomassa Rerumputan dan Pengaruhnya terhadap Tata Air Tanah di Daerah Tangkapan Air Danau Toba. Jurnal Online Agroekoteknologi, 1 (4):1319-1329.
Sutaryo, D. (2009). Penghitungan biomassa, sebuah pengantar untuk studi karbon dan perdagangan karbon. Bogor: Wetlands International Indonesia Programme.

Solikin. 2012. Pertumbuhan Vegetatif dan genertif Stachytarpeta jamaicensis L. Vahl. Jurnal Agroekoteknologi, 2 (1) : 110-119

Sholeha, D.N., Suhartono, dan Lesmana, A. (2018). Pertumbuhan dan kandungan minyak atsiri tanaman selasih (Ocimum basilicum L.) pada naungan dan dosis pupuk fosfat yang berbeda. J. Agron. Indonesia, 46(2):197201. https://doi.org/10.24831/jai.v46i2.20719

Suardhika. (2018). Perbandigan pengaruh lama pengeringan terhadap minyak atsiri kulit jeruk manis (Citrus sinensis) dengan destilasi uap dan identifikasi linalool dengan KLT-Spektrofotodensitometri.. Jurnal Farmasi Udayana, 7 (2): 38-43. https://doi.org/10.24843/JFU.2018.v07.i02.p06

Sumarni, A.N.B. dan Solekan. 2008. Pengaruh volume air dan berat bahan pada penyulingan minyak atsiri. Jurnal Teknologi 1 (1): $83-8$

Warsito. 2018. Deviratisasi sitronelal. Malang : UB Press. 